\title{
Cutaneous Fibroblastic Neoplasm
}

National Cancer Institute

\section{Source}

National Cancer Institute. Cutaneous Fibroblastic Neoplasm. NCI Thesaurus. Code C4634.

A benign or malignant neoplasm arising from the dermis. It is characterized by the presence of neoplastic fibroblasts. 